\title{
Test and Analysis on Seismic Performance of RAC Columns under Different Silica Content
}

\author{
Xiaoyi Quan, Xiangyin Meng and Shimin Zhang \\ School of Civil Engineering, Xijing University, Xi'an 710123, China; \\ 2539390919@qq.com,1032948067@qq.com
}

\begin{abstract}
Keywords: Silica fume; ABAQUS; Skeleton curve; Energy dissipation capacity; Ductility; Bearing capacity
\end{abstract}

\begin{abstract}
In order to study the seismic performance of RAC column silica fume enhanced, this paper selects 1 common RAC column as the control group, and the 3 column contains $4 \%, 6 \%$ RAC and $8 \%$ silica fume as the experimental group, combined with ABAQUS finite element simulation, the RAC column broken ring model, skeleton curve, bearing capacity and ductility, energy dissipation and damage stiffness degradation properties were analyzed. The results show that the finite element simulation results and test results of composite is better, its failure forms are from the column began to crack, and gradually expand upward, until the last column began to appear concrete damage, shedding in doped silica fume content; $6 \%$, is conducive to the improvement of seismic performance the RAC column, but with the increase of silicon content, the lower the ductility of the column, the energy dissipation capacity weakened, stiffness and strength degradation speed.
\end{abstract}

\section{Introduction}

Along with our country city development, building renovation also showed a rapid trend, but also accompanied by a large number of construction waste generated, in response to China's sustainable development, energy saving call, some researchers will waste concrete crushing, washing, sieving into recycled aggregate made of new concrete mixing, so recycled aggregate concrete (Recycled Aggregate Concrete referred to as RAC) came into being, which not only greatly reduce the concrete pressure of abandoned buildings, but also makes the development of a new building materials. At present, many domestic and foreign scholars on the performance of ordinary reinforced concrete has done a lot of research, has achieved fruitful results in [1], but the recycled aggregate concrete, most scholars only focused on the RAC and RAC properties of [2-4] reinforced materials, with little research on seismic performance of reinforced reinforced RAC component performance.

The 4 group of 24 prism specimens, measured the constitutive relation of RAC RAC and silica fume enhanced, and combined with the material performance parameter test, ABAQUS finite element simulation, and the simulation results and the experimental results are compared, the silica content was $0 \%, 4 \%, 6 \%$ and $8 \%$ the RAC column failure pattern, ductility index, deformation capacity and energy dissipation capacity are analyzed, so as to provide a reference for the use of silica fume strengthens the RAC component.

\section{Constitutive relations}

Reinforcement constitutive model. The main mechanical properties of the reinforced bar used in this article are measured by an electronic universal testing machine, such as Figure 1. The basic mechanical properties of the steel bar are shown in Table 1.

In order to simulate the actual situation more accurately, the two fold line model is selected for the constitutive model of the steel bar, and the stress before and after the yield of the steel bar is approximated. The strain relationship is simplified to two oblique lines. Its pre - yield segment.The slope is the elastic modulus of the steel bar itself, and the slope of the rise section after yield is 0.01 
$E_{s}$, and its expression is like formula (1).

$\sigma_{s}= \begin{cases}E_{s} & \varepsilon_{\mathrm{s}} \leq \varepsilon_{\mathrm{y}} \\ f_{y}+E_{S}^{\prime}\left(\varepsilon_{\mathrm{s}}-\varepsilon_{\mathrm{y}}\right) & \varepsilon_{\mathrm{s}} \geq \varepsilon_{\mathrm{y}}\end{cases}$

I

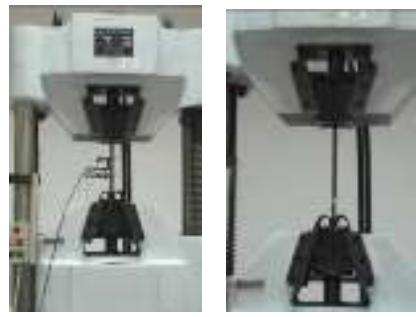

Figure. 1. Determination of mechanical properties of steel bars

\section{concrete constitutive relation}

Test material and mix proportion design. In the study of mechanical properties of recycled concrete, the Qinling Mountains brand 32.5 r Portland cement, recycled coarse aggregate concrete is the demolition of the city after crushing, washing and screening is made, the maximum size of not more than $31.5 \mathrm{~mm}$; the Bahe river sand with natural sand, silica fume (SF) from Shaanxi Lin micro silica source limited. In this experiment, recycled concrete with the substitution rate of $30 \%$ was used as the research object, and its basic coordination, for example, table 1 . According to the standard of the test method of mechanical properties of ordinary concrete (GB/T 50081-2002), the prism of $100 \mathrm{~mm} \times 100 \mathrm{~mm} \times 300 \mathrm{~mm}$ is used as the prism of the specimen as in Figure 2.

Table 1 The mixture ratio used in the test

\begin{tabular}{|c|c|c|c|c|c|c|}
\hline \multirow[b]{2}{*}{$\begin{array}{l}\text { numb } \\
\text { er }\end{array}$} & \multicolumn{6}{|c|}{ Volume per unit volume $(\mathrm{kg} / \mathrm{m} 3)$} \\
\hline & $\begin{array}{c}\text { ceme } \\
\text { nt }\end{array}$ & $\begin{array}{l}\text { wat } \\
\text { er }\end{array}$ & $\begin{array}{l}\text { recycle } \\
\text { d } \\
\text { aggreg } \\
\text { ate }\end{array}$ & $\begin{array}{c}\text { Natura } \\
1 \\
\text { aggreg } \\
\text { ate }\end{array}$ & $\begin{array}{c}\text { Silic } \\
\text { a } \\
\text { fum } \\
\mathrm{e}\end{array}$ & $\begin{array}{c}\text { San } \\
\mathrm{d}\end{array}$ \\
\hline $\mathrm{C}-1$ & 250 & 107 & 180 & 420 & 0 & 233 \\
\hline $\mathrm{C}-2$ & 250 & 107 & 180 & 420 & 4 & 233 \\
\hline $\mathrm{C}-3$ & 250 & 103 & 180 & 420 & 6 & 233 \\
\hline C-4 & 250 & 102 & 180 & 420 & 8 & 233 \\
\hline
\end{tabular}

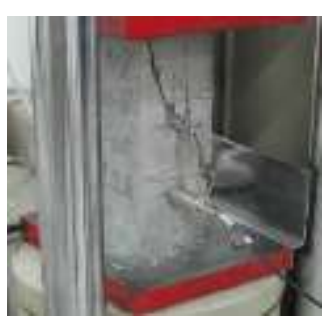

a $(\mathrm{SF}-0 \%)$

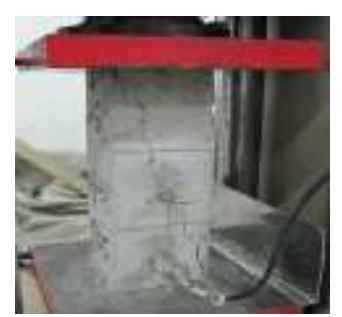

b $(\mathrm{SF}-4 \%)$

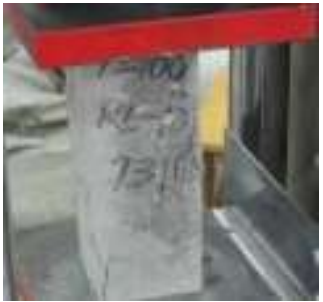

c $(\mathrm{SF}-6 \%)$

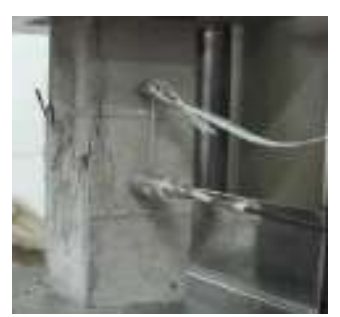

$\mathrm{d}(\mathrm{SF}-8 \%)$

Figure 2. RAC axial compression failure mode

Stress-strain full curve. The equipment used in the test is a microcomputer controlled electro hydraulic servo rigid universal testing machine. The results of the test are the rising section of the stress-strain curve of RAC with different silicon powder content, as shown in Figure 3. By using the least square method to fit the experimental data, for example, the formula (2) takes the dimensionless coordinate as the transverse ordinate 。 


$$
y=A+B x+C x^{2}+D x^{3}
$$

The coefficients related to silica content in RAC are shown in Table 2, which is not very different from the formula in standard GB50010-2010. Therefore, the Hongnestad curve is used to deal with the falling section, such as formula (3):

$$
\sigma_{\mathrm{c}}=f_{c}\left[1-0.151-\frac{\varepsilon_{\mathrm{c}}-\varepsilon_{0}}{\varepsilon_{\mathrm{cu}}-\varepsilon_{0}}\right]
$$

In the formula, ${ }^{\varepsilon_{0}}$ Strain for peak stress, ${ }^{\varepsilon_{\mathrm{c}}}$ Strain corresponding to any point of a curve, $\varepsilon_{\mathrm{cu}}$ Limit pressure strain, $f_{c}$ Peak stress。

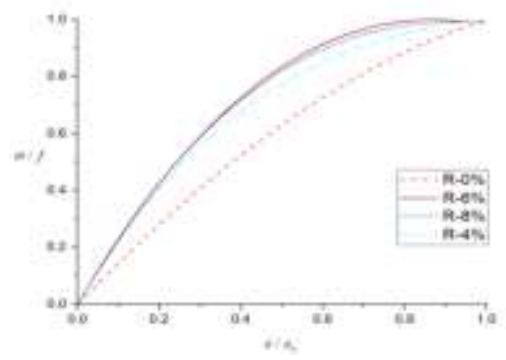

Figure 3. Constitutive relation

Table 2 The curve fitting coefficient table of the RAC stress strain rise section

\begin{tabular}{c|c|c|c|c}
\hline & $\begin{array}{c}\text { RAC30- } \\
0 \%\end{array}$ & $\begin{array}{c}\text { RAC30- } \\
4 \%\end{array}$ & $\begin{array}{c}\text { RAC30- } \\
6 \%\end{array}$ & $\begin{array}{c}\text { RAC30- } \\
8 \%\end{array}$ \\
\hline $\mathrm{A}$ & 0 & 0 & 0 & 0 \\
$\mathrm{~B}$ & 2.37931 & 2.49892 & 2.44243 & 1.50113 \\
$\mathrm{C}$ & -1.95638 & -1.92811 & -1.64199 & -0.4581 \\
& & & & 5 \\
$\mathrm{D}$ & 0.58223 & 0.41784 & 0.17703 & -0.0443 \\
& & & & 9 \\
$\begin{array}{c}\text { Rise section } \\
\text { R2 }\end{array}$ & 0.99995 & 0.98698 & 0.99563 & 0.99865 \\
\hline
\end{tabular}

\section{Finite element modeling}

Test condition. The experiment was conducted in the structure laboratory of Xi'an University Of Architecture And Technology, the RAC reinforced columns, column is in the three layer of frame column through the 1:2 scale model as the research object, component design a total height of 2.15 $\mathrm{m} \mathrm{m}, 1-1$ profile is $250 \mathrm{~mm} * 250 \mathrm{~mm}, 2-2$ bottom beam profile is $500 \mathrm{~mm} * 400 \mathrm{~mm}, 300 \mathrm{~mm}$ on the lower end of the column, with the stirrup spacing for $50 \mathrm{~mm}$ encryption. The bottom beam plays a fixed role, and the geometric size of the concrete column specimen is shown in Figure 4.

During the test, the load displacement mixed control loading method was loaded as shown in Figure 5, according to the ratio of axial compression force applied to the fixed Jack in the column top; the horizontal direction, the load control in the elastic phase, with a difference of 5KN level and negative cyclic loading figure; the displacement control in the yield stage. The positive and negative integer times yield displacement to cyclic loading, 3 cycles per level, until the specimen. 


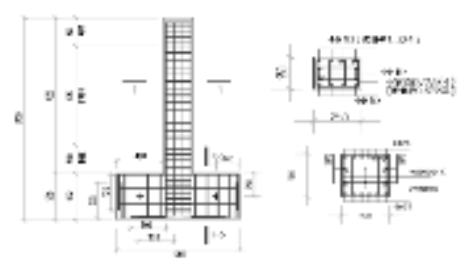

Figure 4. Reinforcement and cross section of specimen

In the ABAQUS finite element modeling, in order to prevent the phenomenon of stress concentration and to avoid directly on the nonlinear material loading, resulting in singular or negative eigenvalues, which results in non convergence phenomenon, so set the stiffness steel pad at load time, ensure the uniform stress, and the connection between the simulation by Tie the steel plate and concrete. In the modeling process, the concrete element is C3D8R and the T3D2 element is used in the concrete unit. Each independent component is created, and the material attributes of each component are given at the same time. Then the assembly is carried out under the Assembly module, and the steel bar is embedded in the concrete unit by the embedded unit. When loading, the force - displacement hybrid control is adopted, the axial force of $270 \mathrm{KN}$ size is applied in Setp-1, the load control is adopted in Setp-2, and the displacement control is adopted in Setp-3. Figure 6 is as follows.

\section{Comparison between finite element results and experimental results}

Destruction form. The content of silica fume is C-3 column $6 \%$ as the research object, obtained by ABAQUS finite element simulation of the concrete stress nephogram of 6 can be seen, with the increase of numerical displacement loading, displacement at the top of the column increases, the shaft stress also increases, and it is not difficult to see that the maximum stress of column, RAC column failure this form is basically consistent with the experimental results as shown in Figure 7, destruction from the column, and the crack gradually expand upward; and silicon content is $4 \%$ and $8 \%$ of the C-2 column and C-4 column, the horizontal thrust is about $40 \mathrm{KN}$, the bottom of the first column reinforced yield, surface crack development rapidly. The ultimate load, the concrete pillar bottom crisp, began to fall off, with increasing content of silica fume, to extend the crack length is longer, the increase of the distance between adjacent cracks.

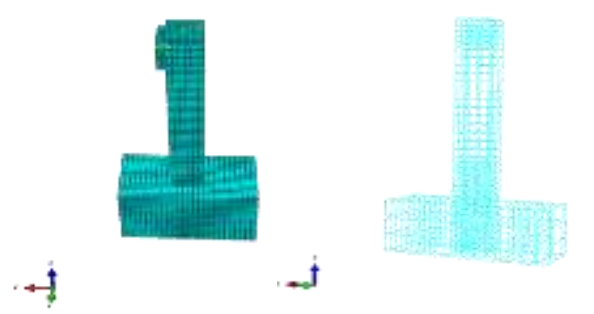

Figure. 5 RAC column finite element model

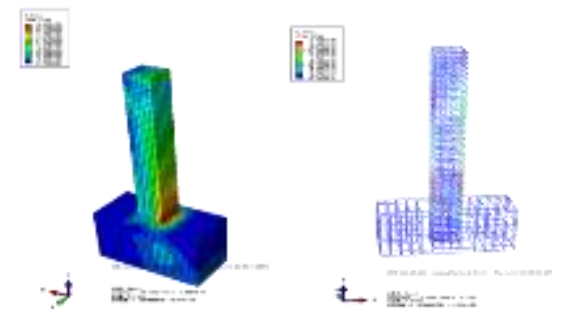

Figure. 6 Finite element simulation

of stress cloud

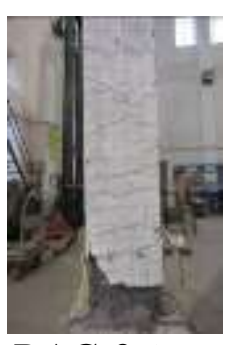

RAC- $0 \%$

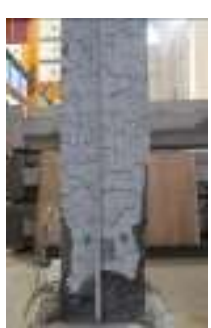

$\mathrm{RAC}-4 \%$

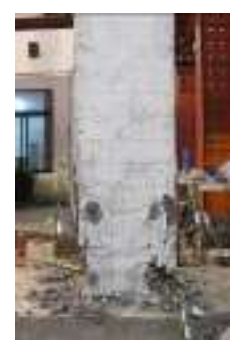

RAC- $6 \%$

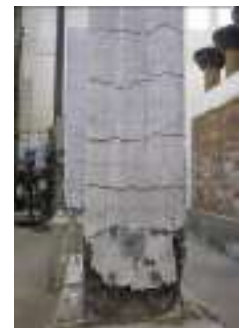

RAC- $8 \%$

Figure 7. Failure mode of RAC column 
Energy dissipation capacity. Under repeated action of earthquake, the energy consumption of components is usually measured by the area surrounded by hysteresis curves. Hysteresis loops are full, surrounded by large areas, indicating that the components absorb strong seismic energy, and vice versa. The equivalent viscous damping coefficient is used as a performance index to evaluate the energy dissipation capacity.

As shown in Fig 8, in the initial stage, the equivalent damping coefficients of C-1, C-2, C-3 and C-4 columns are basically the same. When the lateral displacement reaches $30 \mathrm{~mm}$, the equivalent viscous damping coefficient increases with the increase of lateral displacement, and the energy consumption of RAC column modified by silica fume increases. Compared with the ordinary recycled concrete, the equivalent damping coefficient of RAC column with silicon powder is improved, especially the RAC column with 6\% silicon powder content. The relationship between the cumulative energy and displacement can be seen, with the increase of lateral displacement, energy dissipation of RAC columns are increased, the accumulated energy dissipation of C-3 significantly, but with the silica content reached $8 \%$, energy consumption of C-4 column was less than $\mathrm{C}-3$, therefore, must be conducive to the incorporation of silica fume concrete column to enhance the ability of regeneration energy however, the silica fume incorporation more, but the energy dissipation capacity of the recycled concrete column.
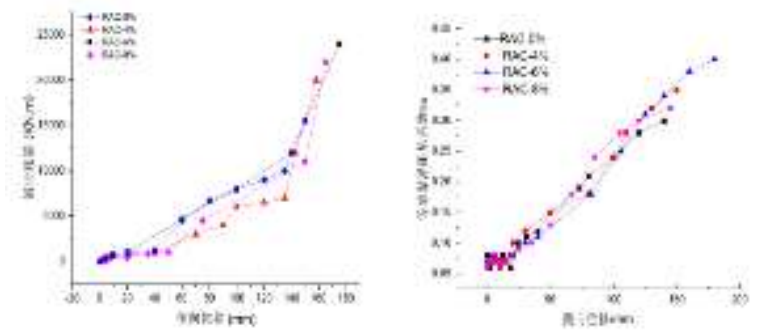

Figure 8. Relation between accumulative energy dissipation and displacement

\section{Conclusion}

ABAQUS in the finite element simulation, the failure mode of RAC reinforced silica column failure form and failure process and test the basic agreement, are from the column starts to break down and then with the increase of load displacement, crack gradually extended to column, and with the increase of silicon content, the decrease of the distance between adjacent shaft crack. When the ultimate load is reached, the concrete at the bottom of the column begins to appear crisp and shedding.

in RAC mixed with a certain content of silica fume, the activity of minerals can promote the formation of excellent gel C-S-H concrete, improved RAC internal pore structure and density, improve the mechanical properties of RAC, the RAC column bearing capacity, ductility, energy dissipation capacity, and higher than the other silicabearing RAC column however, excessive incorporation, it will lead to decrease the performance of RAC.

\section{References}

[1] Over Zhenhai. Principle and analysis of reinforced concrete [M]. Beijing: Tsinghua University press, 2013.(In Chinese)

[2] Xiao Jian Zhuang. Recycled concrete [M]. China Building Industry Press, 2008.(In Chinese)

[3] Zhang Bozhi, Wang Sheliang and so on. Experimental research on basic mechanical properties of recycled concrete [J]. concrete, 2011 (7),p.4-6.(In Chinese)

[4] S. C. KOU, CHI S. POON. DIXON CHAN, Properties of steam

[5] Wan Ao Chou, Li Xiaoyong, Liang rock. Nonlinear analysis of concrete beam column joints based on ABAQUS [J]. Journal of Hunan University of Technology, 2012,26 (5),p.25-29.(In Chinese)

[6] Gao Xiangling, Zhang Yuan da. Nonlinear analysis of nonlinear analysis of reinforced concrete columns under repeated loads, [J]. structural engineer, 2014,30 (3),p.56-63.(In Chinese) 
[7] Yu Jiangtao, Weng Wenfang, Yu Kequan, Lu Zhou guide. The hysteresis performance simulation and analysis of reinforced concrete columns [J]. seismic engineering and engineering vibration, 2014,34,p.389-394.(In Chinese)

[8] Du Yuanfang, Wang Sheliang et al. Experimental study on seismic bearing capacity of FRP reinforced recycled concrete frame joints [J]. Journal of building structures, 2016,37 (4):,p.40-46.(In Chinese) 